\title{
Pressure pain threshold and visual analogue scale changes in the high and low energy extracorporeal shock wave
}

\author{
You-Jin Yang ${ }^{a}$, Seung-Joon Lee ${ }^{b}$, Matthew Choi ${ }^{c}$ \\ ${ }^{a}$ Department of Rehabilitation Medicine, Wonju Medical Center, Wonju, Republic of Korea \\ ${ }^{\mathrm{b}}$ Medical Fitness Center, Jung Hospital, Wonju, Republic of Korea \\ 'Department of Physical Therapy, College of Health and Welfare, Sahmyook University, Seoul, Republic of Korea
}

Objective: This study aims to investigate high energy and low energy extracorporeal shockwave therapy (ESWT) and which one is more effective for shoulder pain.

Design: Single blind randomized controlled trial.

Methods: Fifty two subjects with upper trapezius (UT) trigger point (TrP) participated in this study. They were allocated to high energy $(n=26)$ and low energy group $(n=26)$. This study applies ESWT and investigates the changes of pressure pain threshold (PPT) and visual analogue scale (VAS). The high and low energy groups received focused piezo electric type ESWT $4 \mathrm{~Hz}, 1,000$ pulses and 0.351 and $0.092 \mathrm{~mJ} / \mathrm{mm}^{2}$ respectively. Outcome measures of PPT and pain was measured by algometer and pain VAS. These measurements were performed before and after treatment.

Results: The PPT value was significantly increased in both groups after treatment $(p<0.05)$ and VAS scores were significantly decreased after treatment in both groups $(p<0.05)$. However, there were no significant differences between groups.

Conclusions: ESWT is an effective treatment for the application of the UT TrP. Although there were significant effects of extracorporeal shock wave therapy on PPT and VAS scores, there were no signficant differences between high and low energy extracorporeal shock wave therapy.

Key Words: Extracorporreal shok wave, Trapezius, Trigger point

\section{Introduction}

Myofascial pain syndrome (MPS) is represented by a myofascial trigger point (MTrP). MTrP's are hyper sensitive and when nodules come in contact with a taut band, the sensitive areas of the muscles can cause radiating pain when palpated [1]. Symptoms of MPS include pain and autonomic dysfunction such as abnormal sweating, tearing, redness, and temperature changes [2]. As a result, muscle coordination and work performance is decreased due to increased fatigue and muscle weakness [3].

MPS appears frequently in patients who complain of musculoskeletal pain. MTrP's can be easily found in the neck and shoulder area [4]. Among the shoulder and neck muscles, the upper trapezius (UT) has a high prevalence of MTrP and can cause neck pain and chronic tension-type headaches [5].

The MPS is caused due to an acute trauma, repetitive micro-trauma, or incorrect posture (especially if the rate of static posture or repetitive work is high) [6]. Thus, the purpose of treatment is to inactivate the MTrP by avoiding postures that may cause pain and by having the taut band relax [7,8]. Methods of treatment are Non-steroidal anti-inflammatory drugs, pain relievers such as tramadol [3], dry needling, injection [9], and physical therapy treatments such as ultrasound [10], high-power laser [11], soft tissue mobilizations

Received: 12 September, 2014 Revised: 23 October, 2014 Accepted: 21 November, 2014

Corresponding author: Seung-Joon Lee

Medical Fitness Center, Jung Hospital, 141 Wonmun-ro, Wonju 220-935, Republic of Korea

Tel: 82-33-733-9988 Fax: 82-33-733-9008 E-mail: simon1984@naver.com

(c) This is an Open-Access article distributed under the terms of the Creative Commons Attribution Non-Commercial License (http://creativecommons.org/licens es/by-nc/3.0) which permits unrestricted non-commercial use, distribution, and reproduction in any medium, provided the original work is properly cited.

Copyright @ 2014 Korean Academy of Physical Therapy Rehabilitation Science 
[12].

In the 1990s, extracorporeal shock wave therapy (ESWT) began to be applied to the enthesiopathies, such as pseudoarthrosis, fractures, painful heel, tennis elbow, and tendinitis of the shoulder [13-17]. Application of ESWT treatment for muscle began in the late 1990s [18].

Recently ESWT has been used for the purpose of treating MTrPs and there are a number of studies that have been conducted. Ji et al. [19] reported visual analog scale (VAS) was significantly decreased and pressure pain threshold (PPT) was significantly increased in applying ESWT (energy density of $0.056 \mathrm{~mJ} / \mathrm{mm}^{2}$ ) to the UT TrP group than the placebo group, so that they are suggest ESWT is effective in TrP pain control. In Jeon's study [20], patients with MPS in the trapezius muscle were divide into two groups. The experimental group received ESWT $(4 \mathrm{~Hz}, 0.10$ $\mathrm{mJ} / \mathrm{mm}^{2}, 1,500$ pulses) and the control group received a trigger point injection and transcutaneous electrical nerve stimulation. Both treatments were effective for pain relief and increased range of motion of the neck. Moghtaderi et al. [21] reported patients in the experimental group with plantar fasciitis received ESWT $\left(0.2 \mathrm{~mJ} / \mathrm{mm}^{2}\right)$ for the heel region and for the gastroc-soleus trigger points, while the control group received ESWT just for the heel region. They found there were significantly better results in treatment with the experimental group. Gleitz [22] proposed the technique of ESWT for the UT. Energy level of the focused ESWT was $0.15-0.30 \mathrm{~mJ} / \mathrm{mm}^{2}$.

ESWT has been reported in many studies to be effective in the treatment of MTrP's pain. However, there are divided opinions on the effectiveness because ESWT does not have a clear procedure of the intensity of energy level, frequency, and treatment interval $[23,24]$. Although several studies have been conducted as above, applied energy density is different. Several articles were compared to the effects of high and low energy ESWT application [25,26]. Subjects were patients of enthesiopathy such as rotator cuff tendinitis

Table 1. General characteristics of the subjects

$(\mathrm{N}=52)$

\begin{tabular}{lccc}
\hline \multicolumn{1}{c}{ Characteristic } & $\begin{array}{c}\text { Low energy } \\
\text { group }(\mathrm{n}=26)\end{array}$ & $\begin{array}{c}\text { High energy } \\
\text { group }(\mathrm{n}=26)\end{array}$ & $p$ \\
\hline Age (y) & $29.27(5.65)$ & $25.96(3.56)$ & 0.060 \\
Sex (male:female) & $17: 9$ & $16: 10$ & 0.775 \\
Weight (kg) & $63.62(10.13)$ & $66.19(11.67)$ & 0.379 \\
Height (cm) & $168.12(7.42)$ & $167.92(21.281)$ & 0.479 \\
\hline
\end{tabular}

Values are presented as mean (SD). and calcific tendinitis. However, there are no study was aimed at MTrP. Therefore, at which energy density is the best treatment intensity for MTrP remains unknown. Thus, we wanted to investigate the effects of high-energy and low-energy ESWT when the TrP treatment is applied to the UT.

\section{Methods}

\section{Subjects}

This study was approved by the institutional clinical study review board. For this study we recruited 52 subjects in Jung Hospital, who had pain in their UT. Subject's characteristics are described in Table 1.

Inclusion criteria were determined by the following five criteria: (1) Localization of a palpable taut band within skeletal muscle. (2) Hypersensitive tender spot within taut bands. (3) Local twitch response elicited by a snapping palpation of the taut band. (4) Reproduction of a typical referred pain pattern of the MTrP in response to compression. (5) Recognition of familiar pain patterns. Exclusion criteria were medication or other therapies for MPS, neurological deficits, history of cervical spinal injury and surgery. The study was approved by the institutional ethics committee, and participants signed a written informed consent prior to participation.

\section{Procedures}

For this study we recruited 52 subjects in Jung Hospital, who had pain in their UT. Subjects were allocated by a matched pair randomization design for equivalent distribution according to gender. Thirty-three male subjects and 19 female subjects are divided high energy group (male:female, 17:9) and low energy group (male:female, 16:10). To measure the degree of pain was quantified by the PPT and VAS. This study was conducted in three sequences. First, we located a taut band and MTrP. We then marked the location and the PPT and VAS were tested. Second, ESWT was applied on the marked area. The instrument that was used for the ESWT was the Piezowave, hand-held F10G4 (Richard Wolf, Knittlingen, Germany). In order to prevent lung injury we applied shock wave from theanterior and posterior portion of the marked area and lungs are located in vertically under $2-3 \mathrm{~cm}$ from UT surfaceused $10 \mathrm{~mm}$ depth application (Figure 1) [22]. The high energy group received 4 $\mathrm{Hz}$ and intensity level $10\left(0.351 \mathrm{~mJ} / \mathrm{mm}^{2}\right)$. Low energy group received $4 \mathrm{~Hz}$ and an intensity level $1\left(0.092 \mathrm{~mJ} / \mathrm{mm}^{2}\right)$. The 


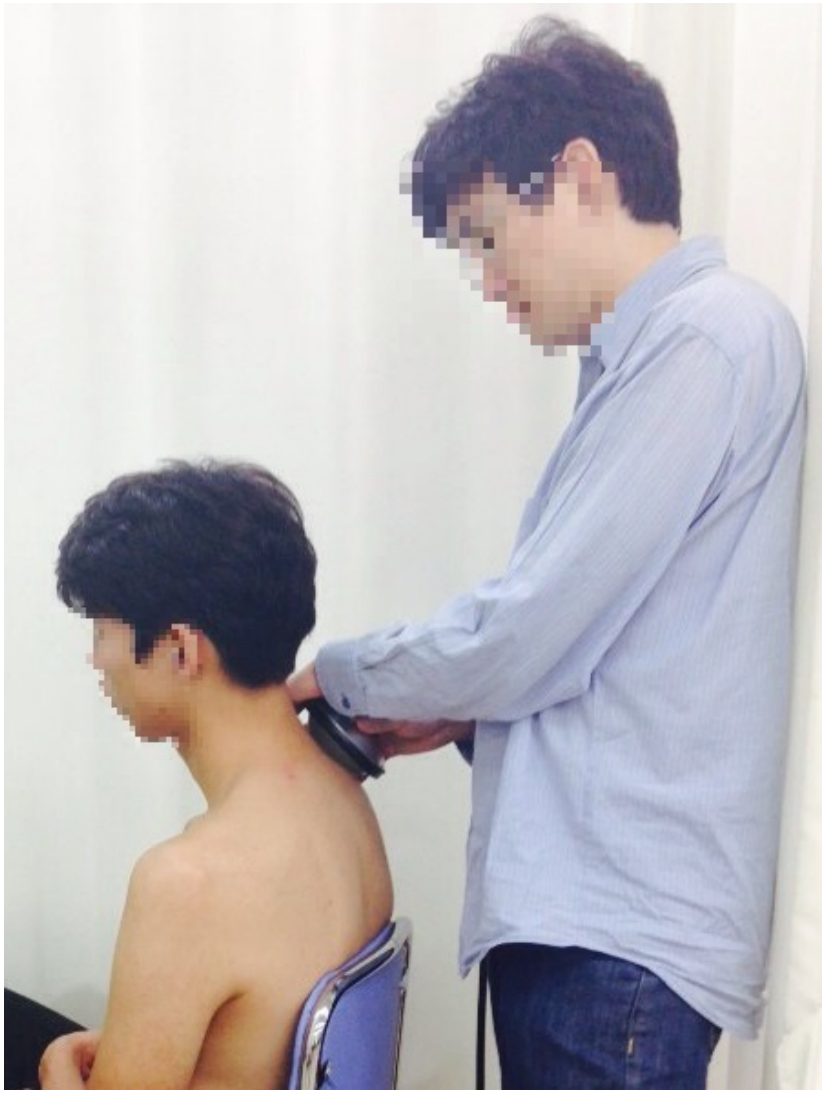

Figure 1. Extracorporeal shock wave therapy application.

number of shock wave was applied to anterior and posterior 500 pulses respectively, total 1,000 pulses received (Figure 1). Lastly, the PPT and VAS was measured again after treatment.

\section{Outcome measures}

\section{Pressure pain threshold}

PPT was measured by Commander Algometer (JTECH Medical, Salt Lake City, UT, USA).The subjects in sitting position and examiner found taut band and MTrP to palpation UT. How to find MTrP was carried out by Simons method [1]. And then mark with aqueous pen. Before the test educated to subjects say 'Stop' or 'Ah' when they feel pain or any uncomfortable feeling from the pressure. Located in algometer to previously marked area and gave pressure constantly $3 \mathrm{~N}$ per second. When subject say 'Stop' or 'Ah' remove the pressure and note measured values [27]. Test was measured 3times before and after the treatment, and for 10 seconds intervals between the test.

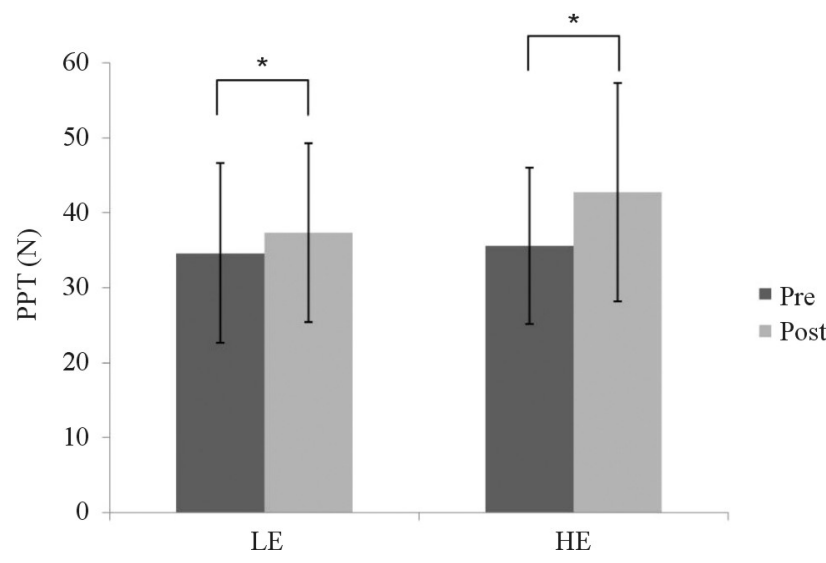

Figure 2. Comparison of pain pressure threshold. PPT: pain pressure threshold, LE: low energy group, HE: high energy group. ${ }^{*}<0.05$.

\section{Visual analogue scale}

Visual analogue scale (VAS) was measured $10 \mathrm{~cm}$ scale. VAS is valid tool for pain intensity level [28]. Examiner explain to subjects, when you feel no pain is ' 0 ' and you feel unbearable pain is 10 . Asked to subjects check the pain rate in parallel line when using Algometer pressed at a pressure of $50 \mathrm{~N}$.

\section{Data analysis}

Data analysis was using IBM SPSS Statistic version 21.0 for Windows (IBM Co., Armonk, NY, USA). Comparison of PPT before and after each group using the paired t-test and comparison between groups, using the independent t-tests were analyzed. Comparison of the VAS before and after using the paired t-test, comparison between groups, using the independent t-tests. The $p$-value was set at 0.05 for all analyses.

\section{Results}

This study is applying the different energy (high or low) of ESWT to the MTrP for the UT muscle and we confirmed the changes in pain level.

Pre-PPT was 34.64 (11.99) for low energy group, 35.67 (10.41) for high energy group. There are no significantly difference between the groups at pre-PPT. Post-PPT was 37.41 (11.90) for low energy group, 42.77 (14.58) for high energy group in which we found a significant difference in each group (Figure 2), but not a significantly difference between the groups (Table 2). 
Table 2. Comparison of PPT and VAS in the high and low energy extracorporeal shock wave $(\mathrm{N}=52)$

\begin{tabular}{|c|c|c|c|c|}
\hline & High energy group $(n=26)$ & Low energy group $(n=26)$ & \multirow{2}{*}{$\mathrm{t}^{\mathrm{a}}$} & \multirow{2}{*}{$p$} \\
\hline & Mean (SD) & Mean (SD) & & \\
\hline \multicolumn{5}{|l|}{ PPT } \\
\hline Pre & $35.67(10.41)$ & 34.64 (11.99) & -0.33 & 0.74 \\
\hline Post & $42.77(14.58)$ & $37.41(11.90)$ & & \\
\hline Change & $7.09(11.66)$ & $2.78(6.19)$ & -1.66 & 0.102 \\
\hline$t^{b}$ & -3.099 & -2.292 & & \\
\hline$p$ & 0.005 & 0.031 & & \\
\hline \multicolumn{5}{|l|}{ VAS } \\
\hline Pre & $5.67(1.66)$ & $5.26(1.65)$ & -0.88 & 0.38 \\
\hline Post & $4.35(1.57)$ & $3.98(1.47)$ & & \\
\hline Change & $-1.32(1.01)$ & $-1.27(0.99)$ & 0.15 & 0.88 \\
\hline $\mathrm{t}^{\mathrm{b}}$ & 6.629 & 6.579 & & \\
\hline$p$ & 0.000 & 0.000 & & \\
\hline
\end{tabular}

Value are presented as mean (SD) or mean (SD) [rank]. PPT: pain pressure threshold, VAS: visual analogue scale. ${ }^{\mathrm{a}}$ Independent t-test. ${ }^{\mathrm{b}}$ Paired t-test

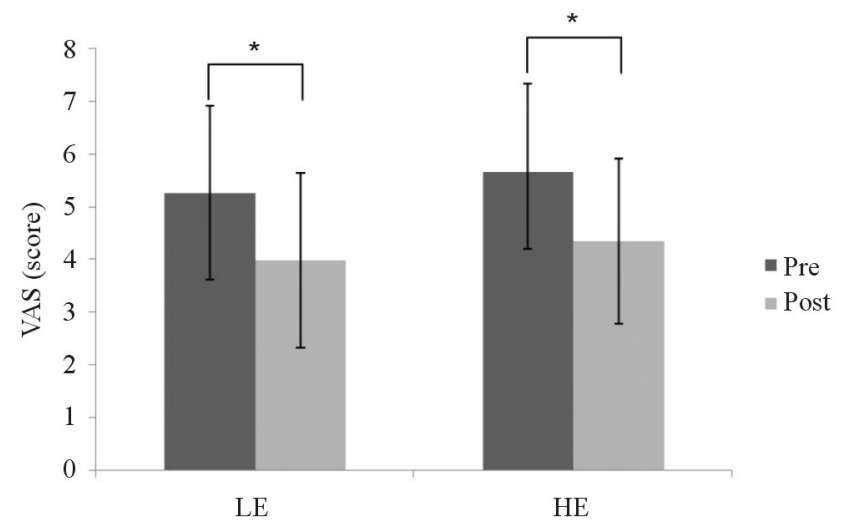

Figure 3. Comparison of visual analogue scale. VAS: visual analogue scale. LE: low energy group, HE: high energy group. ${ }^{*}<0.05$.

Pre-VAS score was 5.26(1.65) for low energy group, 5.67 (1.66) for high energy group. There was no significant difference between the groups at pre-VAS test. Post-VAS score was 3.98 (1.47) for low energy group, 4.35 (1.57) for the high energy group, in which there was significant difference in each group $(p<0.05)$, but no significant difference between the groups (Figure 3).

\section{Discussion}

In this study, we compared the VAS and PPT before and after therapy, finding no significant difference between post treatment of low energy group and high energy group. Pre-post comparisons show that there was an increase in the
PPT and VAS was decreased in the low energy group and high energy group.

The results indicate that these two groups PPT and VAS were improved. The statistical results did not show a significant difference between the high and low energy group. However, the difference between the averages of the PPT, the high energy group was higher. Therefore, we calculated the mean difference divided by the standard deviation (Cohen's $d$ ) to determine the effect size. The effect size is define as small, medium and large effect and the $d$-value is 0.2 , 0.5 and 0.8 respectively [29].

These results are similar to Rompe et al.'s study [26]. They reported effect of extracorporal shock waves of lowversus high energy density in patients with chronic shoulder pain and calcific tendinitis. There are no significant differences between group at first treatment and 6 weeks follow up evaluation. However, there was a significant difference after 24 weeks. In our study, immediately evaluate outcome measure after treatment, it seems to that there was no significant difference between the two groups.

The low energy and high energy group's PPT effect size were 0.45 and 0.61 . This insinuates that the low energy group has a small effect size and the high energy group has medium effect size, and we can conclude that the high energy group is more effective.

This study is important as it is the first designed to randomized controlled, single blinded experiment, which ESWT was applied to different energy densities on MTrP. In addition, PPT's are objectively evaluated by using an 
algometer.

ESWT improves blood circulation in capillary blood vessels and reduces the tension and stiffness of muscles along with the reduction in pain by inducing interference of flow of excessive stimulation of nociceptors and stimulation of nerves. In addition, the study carried out by Hausdorf et al. [30,31], states that ESWT reduces pain in the tissues of the musculoskeletal system through selective destruction of non-myelinated fibers and is effective in reducing the level of substance $\mathrm{P}$ in the dorsal root ganglia. According to Wang et al. [32], ESWT is known to be effective in the acceleration of perfusion in the ischemic tissues (myocardium and skin flap) and stimulates the generation of new blood vessels. According to Davis et al. [33], it is effective in recovering the areas of ischemic skin flap and increasing the perfusion of tissues through a reduction effect on inflammation. According to De Sanctis et al. [34], they thought that ESWT can promote angiogenesis, increase perfusion, and alter the pain signaling at ischemic tissues caused by calcium influx.

This study cannot be generalized for all ages and gender because of the small numbers of subjects, imbalance of gender ratio, and limited age distribution. It was not a double blinded study, so there can be some bias because the examiner knew who was in the low energy group or in the high energy group. Also we did not collect the data of disease duration so we could not prove that there is no significant difference of disease duration between the low energy group and the high energy group.

\section{Conflict of Interest}

The authors declared no potential conflicts of interest with respect to the authorship and/or publication of this article.

\section{References}

1. Simons DG, Travell JG, Simons LS. Myofascial pain and dysfunction: the trigger point manual. 1st ed. Baltimore: Williams \& Wilkins; 1999

2. Fricton JR, Kroening R, Haley D, Siegert R. Myofascial pain syndrome of the head and neck: a review of clinical characteristics of 164 patients. Oral Surg Oral Med Oral Pathol 1985;60:615-23.

3. Borg-Stein J, Simons DG. Focused review: myofascial pain. Arch Phys Med Rehabil 2002;83(3 Suppl 1):S40-7, S48-9.

4. Bron C, de Gast A, Dommerholt J, Stegenga B, Wensing M, Oostendorp RA. Treatment of myofascial trigger points in patients with chronic shoulder pain: a randomized, controlled trial.
BMC Med 2011;9:8.

5. Fernández-de-Las-Peñas C, Cuadrado ML, Pareja JA. Myofascial trigger points, neck mobility, and forward head posture in episodic tension-type headache. Headache 2007;47:662-72.

6. Punnett L, Robins JM, Wegman DH, Keyserling WM. Soft tissue disorders in the upper limbs of female garment workers. Scand $\mathbf{J}$ Work Environ Health 1985;11:417-25.

7. Lavelle ED, Lavelle W, Smith HS. Myofascial trigger points. Med Clin North Am 2007;91:229-39.

8. Fricton JR. Myofascial pain. Baillieres Clin Rheumatol 1994;8:857-80

9. Ay S, Evcik D, Tur BS. Comparison of injection methods in myofascial pain syndrome: a randomized controlled trial. Clin Rheumatol 2010;29:19-23.

10. Aguilera FJ, Martín DP, Masanet RA, Botella AC, Soler LB, Morell FB. Immediate effect of ultrasound and ischemic compression techniques for the treatment of trapezius latent myofascial trigger points in healthy subjects: a randomized controlled study. J Manipulative Physiol Ther 2009;32:515-20.

11. Dundar U, Turkmen U, Toktas H, Solak O, Ulasli AM. Effect of high-intensity laser therapy in the management of myofascial pain syndrome of the trapezius: a double-blind, placebo-controlled study. Lasers Med Sci 2014. [Epub ahead of print]

12. Moraska AF, Stenerson L, Butryn N, Krutsch JP, Schmiege SJ, Mann JD. Myofascial trigger point-focused head and neck massage for recurrent tension-type headache: a randomized, placebo-controlled clinical trial. Clin J Pain 2014. [Epub ahead of print]

13. Heinrichs W, Witzsch U, Bürger RA. Extracorporeal shockwave therapy (ESWT) for pseudoarthrosis. A new indication for regional anesthesia. Anaesthesist 1993;42:361-4.

14. McCormack D, Lane H, McElwain J. The osteogenic potential of extracorporeal shock wave therapy. an in-vivo study. Ir J Med Sci 1996;165:20-2.

15. Rompe JD, Hopf C, Nafe B, Burger R. Low-energy extracorporeal shock wave therapy for painful heel: a prospective controlled single-blind study. Arch Orthop Trauma Surg 1996;115:75-9.

16. Rompe JD, Eysel P, Hopf C, Krischek O, Vogel J, Bürger R, et al. Extracorporeal shockwave therapy in orthopedics. Positive results in tennis elbow and tendinosis calcarea of the shoulder. Fortschr Med 1997;115:26, 29-33.

17. Spindler A, Berman A, Lucero E, Braier M. Extracorporeal shock wave treatment for chronic calcific tendinitis of the shoulder. J Rheumatol 1998;25:1161-3.

18. Kraus M, Reinhart E, Krause H, Reuther J. Low energy extracorporeal shockwave therapy (ESWT) for treatment of myogelosis of the masseter muscle. Mund Kiefer Gesichtschir 1999;3:20-3.

19. Ji HM, Kim HJ, Han SJ. Extracorporeal shock wave therapy in myofascial pain syndrome of upper trapezius. Ann Rehabil Med 2012;36:675-80.

20. Jeon JH, Jung YJ, Lee JY, Choi JS, Mun JH, Park WY, et al. The effect of extracorporeal shock wave therapy on myofascial pain syndrome. Ann Rehabil Med 2012;36:665-74.

21. Moghtaderi A, Khosrawi S, Dehghan F. Extracorporeal shock wave therapy of gastroc-soleus trigger points in patients with plantar fasciitis: a randomized, placebo-controlled trial. Adv 
Biomed Res 2014;3:99.

22. Gleitz M. Myofascial syndromes and trigger points. Shock wave therapy in practice series. Hamburg: Level10; 2011.

23. Buchbinder R, Green SE, Youd JM, Assendelft WJ, Barnsley L, Smidt N. Shock wave therapy for lateral elbow pain. Cochrane Database Syst Rev 2005;(4):CD003524.

24. Louwerens JK, Sierevelt IN, van Noort A, van den Bekerom MP. Evidence for minimally invasive therapies in the management of chronic calcific tendinopathy of the rotator cuff: a systematic review and meta-analysis. J Shoulder Elbow Surg 2014;23:1240-9.

25. Schofer MD, Hinrichs F, Peterlein CD, Arendt M, Schmitt J. High-versus low-energy extracorporeal shock wave therapy of rotator cuff tendinopathy: a prospective, randomised, controlled study. Acta Orthop Belg 2009;75:452-8.

26. Rompe JD, Bürger R, Hopf C, Eysel P. Shoulder function after extracorporal shock wave therapy for calcific tendinitis. J Shoulder Elbow Surg 1998;7:505-9.

27. Fischer AA. Pressure algometry over normal muscles. Standard values, validity and reproducibility of pressure threshold. Pain 1987;30:115-26.

28. Kersten $\mathrm{P}$, White PJ, Tennant A. Is the pain visual analogue scale linear and responsive to change? An exploration using Rasch analysis. PLoS One 2014;9:e99485.

29. Cohen J. A power primer. Psychol Bull 1992;112:155-9.

30. Hausdorf J, Lemmens MA, Heck KD, Grolms N, Korr H, Kertschanska S, et al. Selective loss of unmyelinated nerve fibers after extracorporeal shockwave application to the musculoskeletal system. Neuroscience 2008;155:138-44.

31. Hausdorf J, Lemmens MA, Kaplan S, Marangoz C, Milz S, Odaci E, et al. Extracorporeal shockwave application to the distal femur of rabbits diminishes the number of neurons immunoreactive for substance $\mathrm{P}$ in dorsal root ganglia L5. Brain Res 2008;1207:96-101.

32. Wang CJ, Wang FS, Yang KD, Weng LH, Hsu CC, Huang CS, et al. Shock wave therapy induces neovascularization at the tendon-bone junction. A study in rabbits. J Orthop Res 2003;21:984-9.

33. Davis TA, Stojadinovic A, Anam K, Amare M, Naik S, Peoples $\mathrm{GE}$, et al. Extracorporeal shock wave therapy suppresses the early proinflammatory immune response to a severe cutaneous burn injury. Int Wound J 2009;6:11-21.

34. De Sanctis MT, Belcaro G, Nicolaides AN, Cesarone MR, Incandela L, Marlinghaus E, et al. Effects of shock waves on the microcirculation in critical limb ischemia (CLI) (8-week study). Angiology 2000;51:S69-78. 